\title{
Status of land use intensity in China and its impacts on land carrying capacity
}

\author{
YAN Huimin ${ }^{1,2}$, "LIU Fang ${ }^{1}$, LIU Jiyuan ${ }^{1}$, XIAO Xiangming ${ }^{3,4}$, QIN Yuanwei ${ }^{3}$ \\ 1. Institute of Geographic Sciences and Natural Resources Research, CAS, Beijing 100101, China; \\ 2. University of Chinese Academy of Sciences, Beijing 100049, China; \\ 3. Department of Microbiology and Plant Biology, Center for Spatial Analysis, University of Oklahoma, Norman, \\ OK 73019, USA; \\ 4. Institute of Biodiversity Science, Fudan University, Shanghai 200433, China
}

\begin{abstract}
Land use intensity quantifies the impacts of human activities on natural ecosystems, which have become the major driver of global environmental change, and thus it serves as an essential measurement for assessing land use sustainability. To date, land-change studies have mainly focused on changes in land cover and their effects on ecological processes, whereas land use intensity has not yet received the attention it deserves and for which spatially-explicit representation studies have only just begun. In this paper, according to the degree and reversibility of surface disturbance by human activities, there are four main classes of land use intensity: artificial land, semi-artificial land, semi-natural land, and natural land. These were further divided into 22 subclasses based on key indicators, such as human population density and the cropping intensity. Land use intensity map of China at a 1-km spatial resolution was obtained based on satellite images and statistical data. The area proportions of artificial land, semi-artificial land, semi-natural land, and natural land were $0.71 \%, 19.36 \%$, $58.93 \%$, and $21 \%$, respectively. Human and economic carrying capacity increased with the increase of land use intensity. Artificial land supports $24.58 \%$ and $35.62 \%$ of the total population and GDP, using only $0.71 \%$ of the total land, while semi-artificial land supported $58.24 \%$ and $49.61 \%$ of human population and GDP with $19.36 \%$ of China's total land area.
\end{abstract}

Keywords: land use intensity; land carrying capacity; classification system; spatial pattern

\section{Introduction}

Land use change has become an important driver of biodiversity change and the stability of ecosystem services (Blüthgen et al., 2012; Laliberté et al., 2010; Verburg et al., 2013). Importantly, however, land use change encompasses two aspects: changes in land cover and land use intensity (Erb et al., 2014). Current research in land use science has mainly focused on land cover change and its impacts on processes such as climate change (Lambin et al., 2000, 2001), biodiversity maintenance (Allan et al., 2014), and ensuring food security (Ver-

Received: 2016-08-20 Accepted: 2016-10-12

Foundation: National Key Research and Development Program of China, No.2016YFC0503500, No.2016YFC0503700

Author: Yan Huimin (1974-), PhD, specialized in land use change. E-mail: yanhm@igsnrr.ac.cn

*Corresponding author: Liu Fang (1984-), PhD, specialized in land use change. E-mail: fangliu2015@gmail.com 
burg et al., 2013). Changes in land use intensity - i.e., those subtle but important differences within the same category or unit class of land cover - can have profound impacts on carbon, nitrogen, and water cycles, and on biodiversity and ecological services too, but they have been overlooked until a decade ago (Burney et al., 2010; FAOSTAT, 2011; Green et al., 2005; Sala et al., 2000). Additionally, due to human population growth and increased food consumption that together exacerbate the scarcity of land resources (Dai and Zhu, 2013), the sustainable intensification of land use has become a prime pathway to achieve long-term food and environmental security in China (Foley et al., 2011; Kuemmerle et al., 2013). However, it still remains impossible to accurately quantify the impacts of land use changes on ecological changes and to evaluate the land carrying capacity based solely on land cover maps. The classification methods should be developed to measure the intensity of land use, while these methods should be robust enough to quantify changes in land use intensity in terms of its spatial and temporal patterns, landscape structure, and reversibility of change (Ellis et al., 2010; van Asselen and Verburg, 2012; Verburg et al., 2009; Erb et al., 2014).

Limited land resources and continued population growth, coupled to their related increases in land-based products and services, will ultimately lead to land use intensification (Jiang et al., 2013). Population pressure (Boserup, 1965) and the resulting market incentives it generates (Shriar, 2005; Stone, 2001) will stimulate improvement in the output efficiency of existing land resources by modifying key agricultural practices, such as watering regimes, and agronomic inputs of fertilization and pesticide. These driving factors of land use intensification will in turn determine the spatial differentiation of land use intensity. Therefore, it is sensible to envision that a robust land use classification system should be constructed based not only on the increased demands upon the land but also on agricultural management. Ellis and Ramankutty (2008) developed the first global land use intensity map by combining maps of land cover, irrigation distribution, and population density. Later, Van Asselen and Verburg (2012) classified and mapped land systems at a global scale based on agricultural areas and natural vegetation. Similarly, Václavík et al. (2013) mapped global land system based on compiled datasets of land use intensity and of prevailing environmental and socioeconomic conditions. Nevertheless, our understanding of the spatial patterns of land use intensity in most regions remains weak (Erb et al., 2013; Kuemmerle et al., 2013). In particular, detailed monitoring datasets and spatially explicit maps are required to characterize land use intensity (Zhu and Sun, 2014). Unfortunately, current land use intensity datasets are only available at a coarse resolution $(10 \mathrm{~km})$, thus precluding the detailed information needed on the spatial heterogeneity of land use intensity. Additionally, most research into cropland use intensity is performed by integrating information on patterns of irrigation and livestock population density, neglecting the important characterization of the intensity of the cropping process itself.

At the turn of this century, China embarked on new paths of urbanization and industrialization, and underwent a transition from land market formation to ensuring cultivated land protection and ecological development (Xu et al., 2003). Therefore, land use intensity in China presented new features in this period: accelerated urbanization led to the urban encroachment on farmland (Liu et al., 2010); regional development strategies such as "Grand Western Development Program," "Revitalization of Northeast China," and "Rise of Central 
China" accelerated labor migration (Liu et al., 2010), and the resulting decreased farmer labor would leave more extensively used agricultural areas (Xie and Jiang, 2016); the implementation of national agricultural supporting policies would encourage farmers to grow grain crops (Song and Ouyang, 2012) for more intensive farmland use (Jiang et al., 2013); national key forestry and ecological protection projects gained new forest, while large areas of native forests were converted into cash crops (Li et al., 2007); "Returning Grazing Land to Grassland Project" had restored grassland ecosystem to a certain extent (Zhang et al., 2015), but the livestock and forage balance management policy would promote the conversion from native grassland to artificial grassland, leading to more intensive use of grassland (Xu, 2014). Hence, a clear and detailed understanding of land use intensity in China for the year 2000 is a primary task to achieve harmony among ecological, economic, and social systems, which will provide a baseline reference for evaluating future change and its sustainability. However, current research in China often targets cropland and built-up land, leaving other land types less studied. Household surveys and field questionnaires at provincial and regional scales (Hao and Li, 2011; Hua et al., 2013) may provide detailed representations of land use intensity, but they are not suitable over a broad geographical area because they are labor- and time-intensive. Instead, for such large-scale analysis, the agricultural censuses available at the provincial and county scales have been widely used to map land use intensity without detailed spatial variations (Chen and Li, 2009; Li and Fang, 2014; Liu and Li, 2006; Wu and Qu, 2007; Yao et al., 2014; Zhang et al., 2005). So far, however, mapping land use intensity at a fine spatial resolution with national coverage has not been reported in China.

By integrating land use datasets with spatially explicit indicators, we first developed a land use intensity classification system and then mapped land use intensity in China at a 1-km spatial resolution. Second, the spatial differentiation of land use intensity was characterized at three relevant scales of interest: national, regional, and provincial. Third, and finally, the linkages between land use intensity and land carrying capacity were explored and examined. The study provides the methodology and data basis for a trajectory dynamics analysis of land use intensity as driven by economic development and ecological protection, and thereby offers timely guidance for sustainable land management.

\section{Data and methodology}

\subsection{Data sources and processing}

Spatially explicit indicators crucial for measuring land use intensity included the following: land use, irrigated and rain-fed croplands, cropping intensity, human population density, and livestock population density. For the linkage analysis between land use intensity and land carrying capacity, in addition to human population density, the gross domestic product (GDP) and net primary productivity (NPP) were also applied.

\subsubsection{Land use}

The land use map for 2000 was obtained from China's National Land Use/Cover Dataset (NLCD). The dataset used a mapping scale of 1:100,000, and it was generated from the ma- 
manual digitalization of Landsat TM/ETM images acquired in 1999/2000, which were cross validated through extensive field survey datasets (Liu et al., 2014). A grid fraction dataset at a 1-km spatial resolution was obtained by calculating the area fractions of each land use type.

\subsubsection{Irrigated and rain-fed croplands}

This dataset came from Global Food Security-Support Analysis Data (GFSAD1000 V1.0, http://geography.wr.usgs.gov/science/croplands/), and was derived at the nominal 1-km scale based on current global cropland products having reliable data quality (Friedl et al., 2010; Pittman et al., 2010; Thenkabail et al., 2009, 2011; Yu et al., 2013). The dataset was shown to be applicable to our study through a correlated analysis with statistical data at the county scale.

\subsubsection{Cropping intensity}

Cropping intensity refers to the crop frequency for a given cropland area on a per year basis, which is important to properly characterize the levels of cropland use intensity. National cropping intensity in 2000 derived from MODIS data using the peak detect method, which integrated the datasets of smoothed EVI time series (500 m, 8-day intervals) and agro-meteorological and phenology records (Yan et al., 2008, 2010, 2014).

\subsubsection{Human population density}

Human population has been widely used to indicate the intensity of human-environment interactions (Boserup, 1965; Ellis and Ramankutty, 2008). In this paper, human population density was used to quantify land use intensity in forests by overlaying a human population density map to a forest map. County-level human population density was applied to measure the intensity of water use. The gridded population density database of China in 2000 was provided by Data Center for Resources and Environmental Science, Chinese Academy of Sciences (RESDC) (http://www.resdc.cn). The grid cell $\left(1 \mathrm{~km}^{2}\right)$ represented the total population within a given square kilometer. Furthermore, the gridded Population of the World (GPW) (http://sedac.ciesin.columbia.edu/data/collection/gpw-v3) was used to fill in the missing data for Taiwan. Following the study done by Ellis and Ramankutty (2008), human population density was divided into three levels: a high population density $\left(>100\right.$ persons $\left./ \mathrm{km}^{2}\right)$, a low population density $\left(1-100\right.$ persons $\left./ \mathrm{km}^{2}\right)$, and negligible population density $\left(<1\right.$ person $\left./ \mathrm{km}^{2}\right)$.

\subsubsection{Livestock population density}

Differences in livestock population density can help distinguish grassland use intensity. The livestock population density dataset came from Gridded Livestock of the World (GLW), at a spatial resolution of $1 \mathrm{~km}$ (Robinson et al., 2014). The database contained the global distribution maps for the main species of livestock, which was created by integrating multi-source datasets. The measure of Tropical Livestock Units (TLU) was used to aggregate different livestock types and sizes (Petz et al., 2014). We classified TLU into three levels based on a Jenks natural break optimization technique: a high population density $\left(>10 \mathrm{TLU} / \mathrm{km}^{2}\right)$, a low population density $\left(1-10 \mathrm{TLU} / \mathrm{km}^{2}\right)$, and negligible population density $\left(<1 \mathrm{TLU} / \mathrm{km}^{2}\right)$.

\subsubsection{Net primary productivity}

National NPP data in 2000 at a spatial resolution of $500 \mathrm{~m}$ was simulated using the Vegetation Photosynthesis Model (VPM). The remote sensing-based light use efficiency model had been developed by Xiao et al. (2004a, 2004b); it used MODIS data and flux observation 
data. The data was resampled to a fixed scale of $1 \mathrm{~km}$ for spatial consistency and used with the land use intensity results.

\subsubsection{Gross domestic product}

The gridded GDP map of China in 2000 was provided by the Data Center for Resources and Environmental Science, Chinese Academy of Sciences (RESDC) (http://www.resdc.cn). The $1-\mathrm{km}$ grid cell represented the total GDP within a given square kilometer.

\subsection{Land use intensity classification system}

As defined by Anderson et al. (1976), the ideal land use intensity classification system should meet the following criteria: (1) be applicable over extensive areas; (2) have comprehensive classes covering the whole area; (3) have hierarchical classes allowing subcategories aggregation and categories disaggregation; (4) use a classification procedure repeatable by different operators at any time; (5) have a dominant class in each grid cell.

Land use intensity measures the impact of human activities on natural ecosystems, so its associated metrics should reflect the spatial pattern, temporal intensity, landscape structure, and degree of reversibility of human effects. According to the degree and reversibility of land surface disturbance by human activities, we divided land use into four main classes (Table 1): (1) artificial land, i.e., impervious surface area with irreversible effects; (2) semi-artificial land, characterized by surface soil that is frequently disturbed; (3) seminatural land, characterized by occasionally disturbed surface soil but frequently disturbed vegetation; (4) natural land, with no human disturbance of the surface soil and native vegetation. These four classes were further divided into 22 subclasses. Artificial land was divided into two categories: urban vs. village and others. Semi-artificial land consisted of triplecropping paddy, double-cropping paddy, single-cropping paddy, irrigated triple-cropping dryland, irrigated double-cropping dryland, irrigated single-cropping dryland, rain-fed triple-cropping dryland, rain-fed double-cropping dryland, rain-fed single-cropping dryland, and fallow land according to their combined cropping intensity and water conditions. Semi-natural land was classified into three levels (high intensity, low intensity, and natural) each for forest, grassland, and water body types according to local human population density. Natural land referred to unused land including sandy land, Gobi, salina, wetland, bare soil, and bare rock.

\section{Results}

\subsection{Spatial patterns of land use intensity in China}

Spatial patterns of land use intensity at the national, provincial and county scales were analyzed to characterize the spatial differentiation of land use intensity.

\subsubsection{Land use intensity at the national scale}

In China, semi-natural land covered the majority China's land surface, at $58.93 \%$, followed by natural land $(20.99 \%)$ and semi-artificial land (19.36\%), while artificial land covered the least proportion $(0.71 \%)$. Urban, as well as village and others, both covered a similar proportion of artificial land area. Considering semi-artificial land, rain-fed single-cropping dryland covered the greatest area proportion (34.69\%), followed by irrigated single-cropping 
Table 1 Land use intensity classification system

\begin{tabular}{|c|c|c|}
\hline Class & Subclass & Description \\
\hline \multirow{2}{*}{$\begin{array}{l}\text { Artificial land } \\
\text { (Built-up land) }\end{array}$} & Urban & Dense built environments with very high population density \\
\hline & Village and others & $\begin{array}{l}\text { Rural settlements, factories, and transportation facilities with high } \\
\text { population but fragmented landscape }\end{array}$ \\
\hline \multirow{10}{*}{$\begin{array}{l}\text { Semi-artificial } \\
\text { land (Cropland) }\end{array}$} & Triple-cropping paddy & Cropland mainly for triple paddy rice \\
\hline & Double-cropping paddy & Cropland mainly for double paddy rice \\
\hline & Single-cropping paddy & Cropland mainly for single paddy rice \\
\hline & Irrigated triple-cropping dryland & Dryland mainly for irrigated triple crop \\
\hline & Irrigated double-cropping dryland & Dryland mainly for irrigated double crop \\
\hline & Irrigated single-cropping dryland & Dryland mainly for irrigated single crop \\
\hline & Rain-fed triple-cropping dryland & Rain-fed dryland with triple cropping \\
\hline & Rain-fed double-cropping dryland & Rain-fed dryland with double cropping \\
\hline & Rain-fed single-cropping dryland & Rain-fed dryland with single cropping \\
\hline & Fallow land & Cropland left idle during the growing season \\
\hline \multirow{9}{*}{$\begin{array}{l}\text { Semi-natural } \\
\text { land (Forest, } \\
\text { Grassland, } \\
\text { Water body) }\end{array}$} & High intensity forest & Forest with high human population density $\left(>100\right.$ persons $\left./ \mathrm{km}^{2}\right)$ \\
\hline & Low intensity forest & Forest with low human population density $\left(1-100\right.$ persons $\left./ \mathrm{km}^{2}\right)$ \\
\hline & Natural forest & Forest with negligible human population density $\left(>1\right.$ person $\left./ \mathrm{km}^{2}\right)$ \\
\hline & High intensity grassland & Grassland with high livestock population density $\left(>10 \mathrm{TLU} / \mathrm{km}^{2}\right)$ \\
\hline & Low intensity grassland & Grassland with low livestock population density $\left(1-10 \mathrm{TLU} / \mathrm{km}^{2}\right)$ \\
\hline & Natural grassland & Grassland with negligible livestock population density $\left(<1 \mathrm{TLU} / \mathrm{km}^{2}\right)$ \\
\hline & High intensity water body & $\begin{array}{l}\text { Water body located in county with high human population density } \\
\left(>100 \text { persons } / \mathrm{km}^{2}\right)\end{array}$ \\
\hline & Low intensity water body & $\begin{array}{l}\text { Water body located in county with low human population density } \\
\left(1-100 \text { persons } / \mathrm{km}^{2}\right)\end{array}$ \\
\hline & Natural water body & $\begin{array}{l}\text { Water body located in county with negligible human population } \\
\text { density }\left(<1 \text { person } / \mathrm{km}^{2}\right)\end{array}$ \\
\hline $\begin{array}{l}\text { Natural land } \\
\text { (Unused land) }\end{array}$ & Unused land & Sandy land, Gobi, salina, wetland, bare soil and bare rock \\
\hline
\end{tabular}

dryland (18.29\%). Among different land cover types of semi-natural land, the highest intensity occurred under water body, for which area proportions of high and low intensity levels were $32.17 \%$ and $43.21 \%$, respectively. Ranked second in intensity after water body was grassland, for which area proportions of high and low intensity were $23.46 \%$ and $34.54 \%$, respectively. Among forest types, natural forest accounted for the largest area proportion (56.09\%), followed by low (24.83\%) and high $(24.83 \%)$ intensity forest.

Spatial patterns in land use intensity showed that, as indicated by the boundary of $\mathrm{Hu}$ Line, the southeastern part with its denser human population was more intensively used than the northwestern part with its sparse population (Figure 1). Statistics on land use intensity classes were performed every $1^{\circ}$, in both latitudinal and longitudinal directions. In the latitudinal direction, the area proportion of natural land between $31.5^{\circ} \mathrm{N}$ and $39.5^{\circ} \mathrm{N}$ latitude accounted for over $20 \%$, and reached its peak value between $35.5^{\circ} \mathrm{N}$ and $37.5^{\circ} \mathrm{N}$ latitudes wherein the Taklimakan desert was located. In the longitudinal direction, a transition in the dominant land use intensity class was from natural and semi-natural land to semi-natural and semi-artificial land with the increment of longitude. 


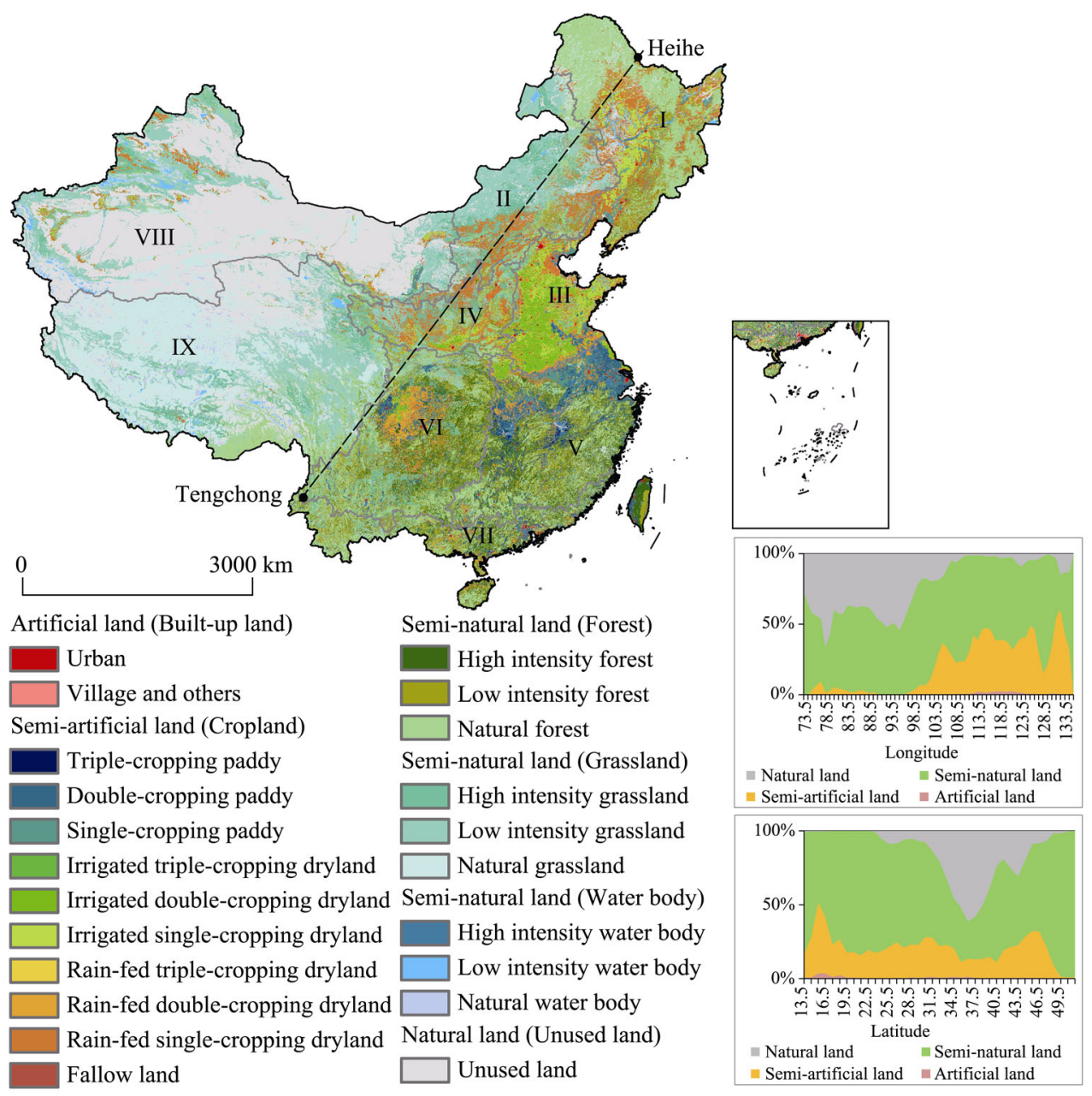

Figure 1 Land use intensity map of China in 2000. Ecological Regions include Northeast Region (I), Inner Mongolia and the Great Wall Region (II), Huang-Huai-Hai Region (III), Loess Plateau Region (IV), Middle and Lower Reaches of the Yangtze River Region (V), Southwest Region (VI), South China Region (VII), Gan-Xin Region (VIII) and Qinghai-Tibet Region (IX).

\subsubsection{Land use intensity at regional scale}

Land use intensity classes showed remarkable spatial differentiation across different Ecological Regions (henceforth refer to both Table 2 and Figure 2). Artificial land was mainly distributed in Huang-Huai-Hai Region, Middle and Lower Reaches of the Yangtze River Region, South China Region, and Northeast Region. In particular, Huang-Huai-Hai Region had the largest area of built-up land, while Middle and Lower Reaches of the Yangtze River Region and Sichuan Basin had a higher intensity, with urban area accounting for $>70 \%$ of the built-up area. Semi-artificial land was primarily located in Huang-Huai-Hai Region, Middle and Lower Reaches of the Yangtze River Region, and Northeast Region. Middle and Lower Reaches of the Yangtze River Region, South China Region, and Sichuan Basin had the highest cropland use intensity wherein paddy rice farming accounted for $71.29 \%$, $45.70 \%$, and $30.42 \%$ of cropland area in use, respectively. Cropland with multiple cropping 
Table 2 Proportions of land area under four land use intensity classes in 9 ecological regions of China (\%)

\begin{tabular}{lcccc}
\hline \multicolumn{1}{c}{ Regions } & Artificial land & Semi-artificial land & Semi-natural land & Natural land \\
\hline Northeast Region & 13.20 & 17.88 & 10.12 & 2.20 \\
Inner Mongolia and the Great Wall Region & 5.42 & 8.74 & 10.22 & 2.87 \\
Huang-Huai-Hai Region & 35.57 & 19.22 & 1.09 & 0.11 \\
Loess Plateau Region & 5.10 & 8.81 & 4.23 & 0.07 \\
Middle and Lower Reaches of the Yangtze & 15.98 & 18.81 & 10.80 & 0.10 \\
River Region & & & 12.99 & 0.03 \\
Southwest Region & 4.64 & 14.65 & 6.56 & 0.02 \\
South China Region & 13.62 & 6.15 & 12.89 & 70.93 \\
Gan-Xin Region & 5.78 & 5.07 & 31.09 & 23.67 \\
Qinghai-Tibet Region & 0.70 & 0.66 & & \\
\hline
\end{tabular}

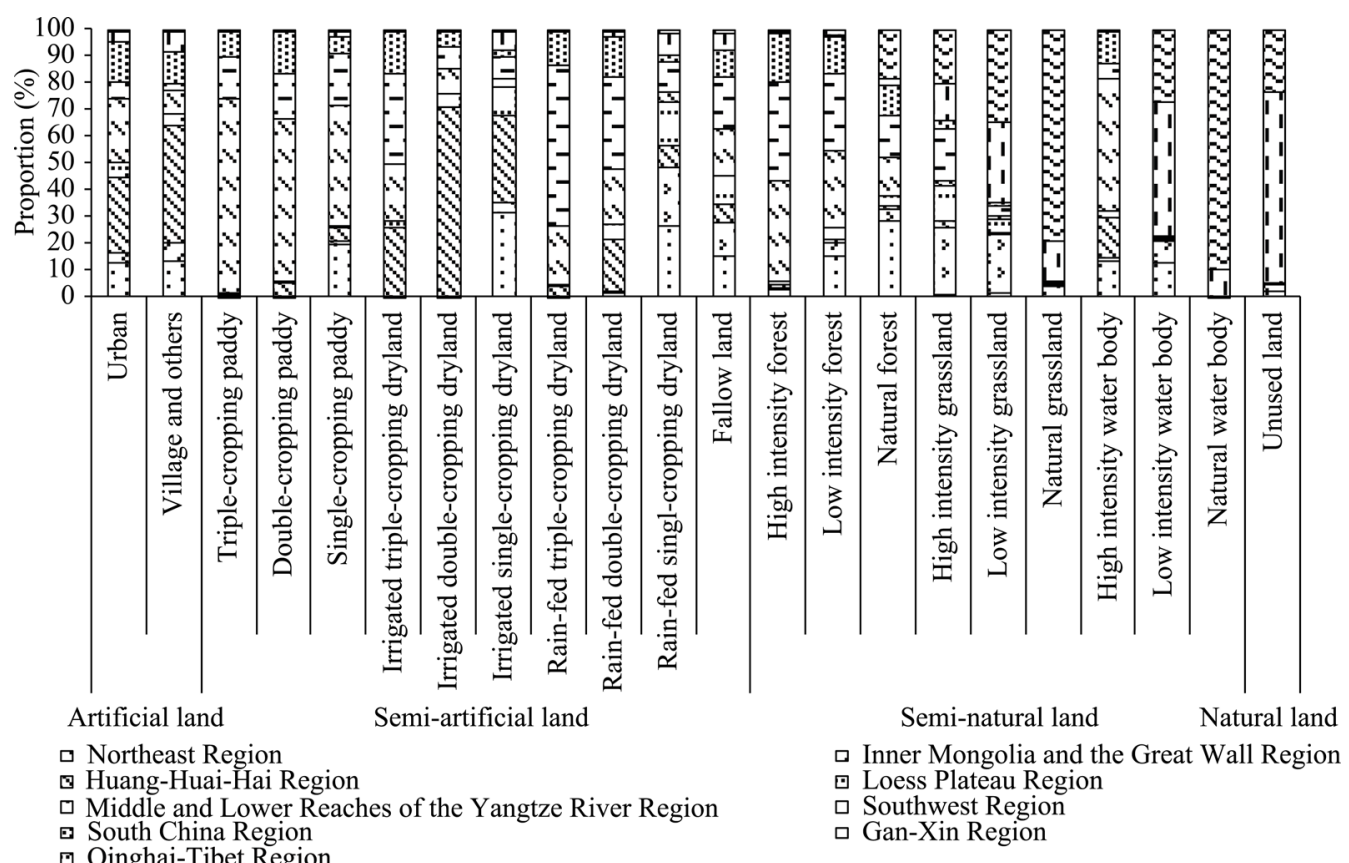

Figure 2 Area proportions of the 22 land use intensity subclasses distributed in 9 ecological regions of China

practices accounted for $58.11 \%, 64.35 \%$, and $44.57 \%$ of the area in these regions, respectively. Beyond these regions, Huang-Huai-Hai Region had 76\% sum of irrigated dryland and paddy rice, and comparable proportions of single- and double-cropped land which added up to $98.40 \%$ of the total cropland.

Irrigated dryland and paddy rice added up to $46.02 \%$ of the total cropland in Northeast Region, in which $13.40 \%$ of the area was single-cropping paddy rice. Where dominated by the single-cropping practice, Inner Mongolia and the Great Wall Region, Qinghai-Tibet Region, Loess Plateau Region, and Gan-Xin Region had the lowest cropland use intensity with rain-fed dryland accounting for $86.94 \%, 72.92 \%, 68.86 \%$, and $63.08 \%$ of the total cropland, respectively. Qinghai-Tibet Region had the largest area of semi-natural land, followed by Southwest Region, and Gan-Xin (Gansu-Xinjiang) Region. Huang-Huai-Hai Region had the 
highest proportion of high intensity level of semi-natural land (55.94\%), while Northeast Region and Qinghai-Tibet Region had lower intensity with natural land covering the largest area proportion.

Forest was mainly distributed in the Northeast Region, Middle and Lower Reaches of the Yangtze River Region, Southwest Region, and South China Region. However, Middle and Lower Reaches of the Yangtze River Region and Southwest Region had the highest intensity, with high and low intensity forest covering $63.47 \%$ and $62.41 \%$ of the total forest area, respectively. South China Region ranked second, with high and low intensity forest together accounting for $52.92 \%$. The Northeast Region was dominated by natural forest, which accounted for $78.28 \%$ of the total forest area found in this region. Grassland use intensity decreased in the following order: Inner Mongolia and the Great Wall Region, Gan-Xin Region, and Qinghai-Tibet Region. Inner Mongolia and the Great Wall Region had the largest proportion of high intensity grassland, which accounted for $38.01 \%$ of total grassland in this region. Natural land covered the largest proportion (58.51\%) in Qinghai-Tibet Region, with high intensity grassland distributed in local area. Water body in Middle and Lower Reaches of the Yangtze River Region had the highest land use intensity because of its dense human population; meanwhile, Huang-Huai-Hai Region was found to have high pressure on its water resources. Natural land was concentrated in Gan-Xin Region and Qinghai-Tibet Region, both of which have sparse human populations. Not surprisingly, Gan-Xin Region had the largest natural land because it contains a vast desert.

\subsubsection{Land use intensity at the provincial scale}

Significant spatial variation in land use intensity was also observed among the provinces in China (Figure 3). Considering artificial land, Shandong province had the largest area proportion of it followed by Jiangsu province, Hebei province, Guangdong province, and Henan province, which had proportions of $12.03 \%, 8.87 \%, 8.85 \%, 7.84 \%$, and $7.07 \%$, respectively. The area of semi-artificial land in provinces of Heilongjiang, Henan, Sichuan, Shandong,

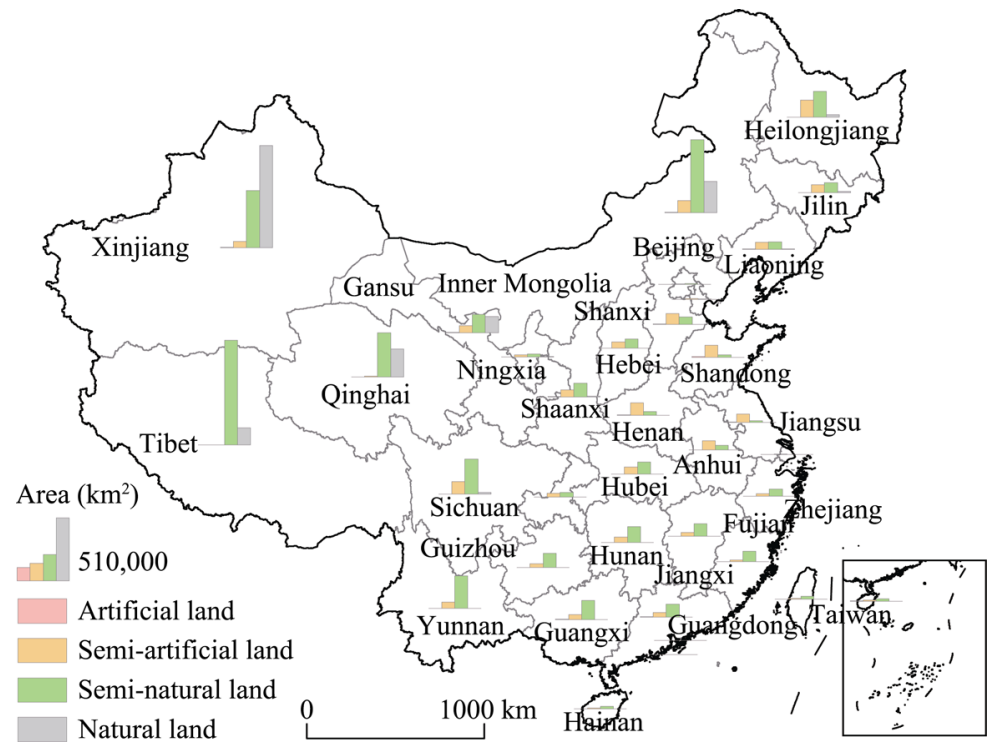

Figure 3 Area statistics on the land use intensity classes in each province of China 
Inner Mongolia, and Hebei exceeded $10 \times 10^{4} \mathrm{~km}^{2}$ in each case. Semi-natural land was widely distributed in Tibet, Inner Mongolia, and Xinjiang with corresponding area proportions of $18.36 \%, 12.82 \%$, and $10.05 \%$ of total semi-natural land in China. Notably, 50.05\% of natural land in China was located in Xinjiang, followed by Inner Mongolia and then Tibet. Artificial land exceeded 10\% in each of the following: Macao, Hong Kong, Shanghai, Tianjin and Beijing. The area proportions of semi-artificial land in provinces of Jiangsu, Shandong, and Henan each exceeded 70\%, while those of Tianjin, Hebei and Anhui each exceeded 50\%. Semi-natural land covered most of the total area in Tibet, at $85.41 \%$. The 17 provinces with an area proportion of semi- natural land exceeding 60\% were mainly distributed in southern and western China. Natural land in Xinjiang accounted for $61.63 \%$, which was much higher than seen for the other Chinese provinces.

Provinces were divided into three categories according to their geographical locations: Eastern, Central, and Western (see Fang and Wang, 2015). The land use intensity in the Eastern provinces was the highest, followed by Central and Western provinces. The total area with semi-natural and semi-artificial land in both Eastern and Central provinces together amounted to $96 \%$. In contrast, the Western provinces were mainly featured with semi-natural land and natural land, which together added up to $90 \%$ of the total area (Figure 4). In terms of the land use intensity subclasses (Figure 5), the Eastern provinces had average proportions of urban, villages and others, paddy rice, irrigated cropland, and high intensity forest that exceeded counterparts in Central and Western provinces. The area proportion of irrigated dryland was greater than that of paddy rice in Central provinces, whereas the unused land covered the largest proportion of area in Western provinces, followed by grassland. Finally, the area proportion of high intensity grassland in Western China

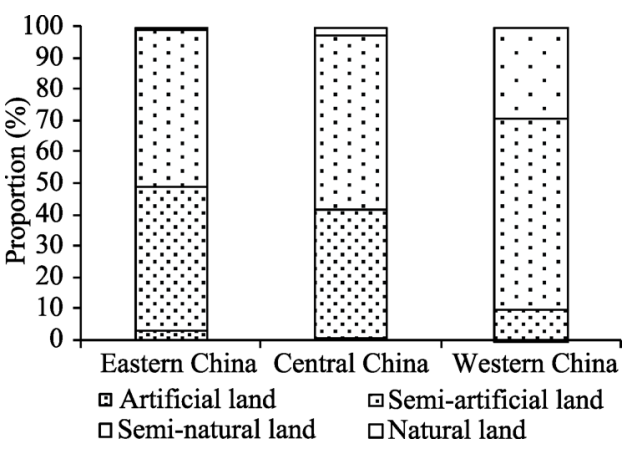

Figure 4 Proportions of the four land use intensity classes in Eastern, Central, and Western China

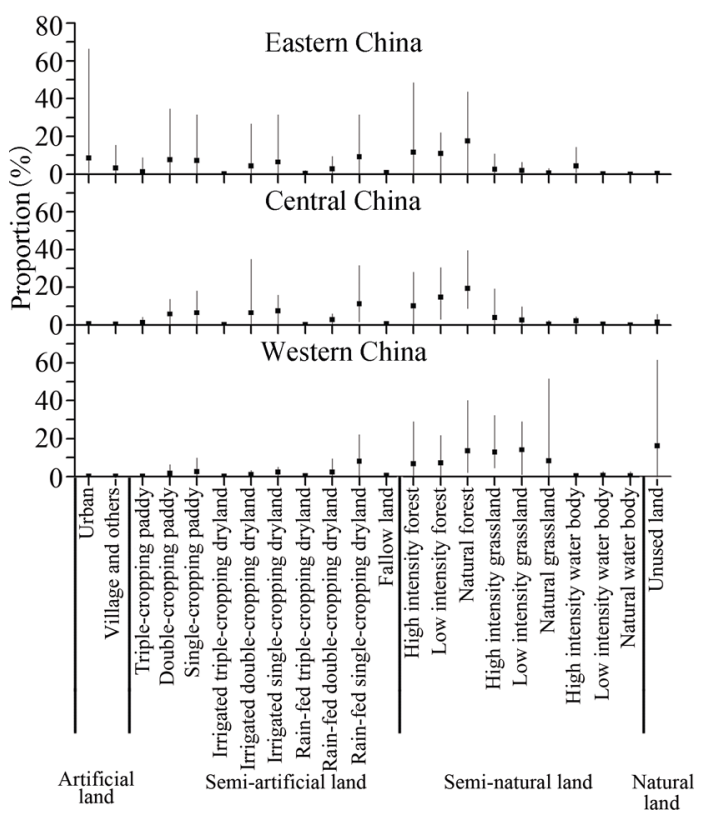

Figure 5 Proportions of the land use intensity subclasses in Eastern, Central, and Western China (diamonds are means, error bars depict min-max range) exceeded that found in the Eastern and Central provinces.

\subsection{Linking China's land use intensity to its land carrying capacity}

In order to explore the relationship between land use intensity and land carrying capacity, 
indicators such as population carrying capacity, economic carrying capacity, supporting capacity, and land use efficiency were selected for this study. Population density and gross domestic product (GDP) represent the size of human and economy. Net primary productivity (NPP) indicates the supporting capacities of natural systems. The ratio of GDP to NPP quantifies land use efficiency.

Spearman rank correlation analysis showed that land use intensity was positively correlated with population carrying capacity as well as the economic carrying capacity ( $\mathrm{r}=0.902$, $\mathrm{p}<0.01 ; \mathrm{r}=0.876, \mathrm{p}<0.01$ ). In terms of land use intensity classes (Figures $6 \mathrm{a}$ and $6 \mathrm{~b}$, respectively), artificial land had the highest carrying capacity for both human population and economy, with average values of 4755.20 persons $/ \mathrm{km}^{2}$ and $5423.53 \times 10^{4}$ yuan $/ \mathrm{km}^{2}$,
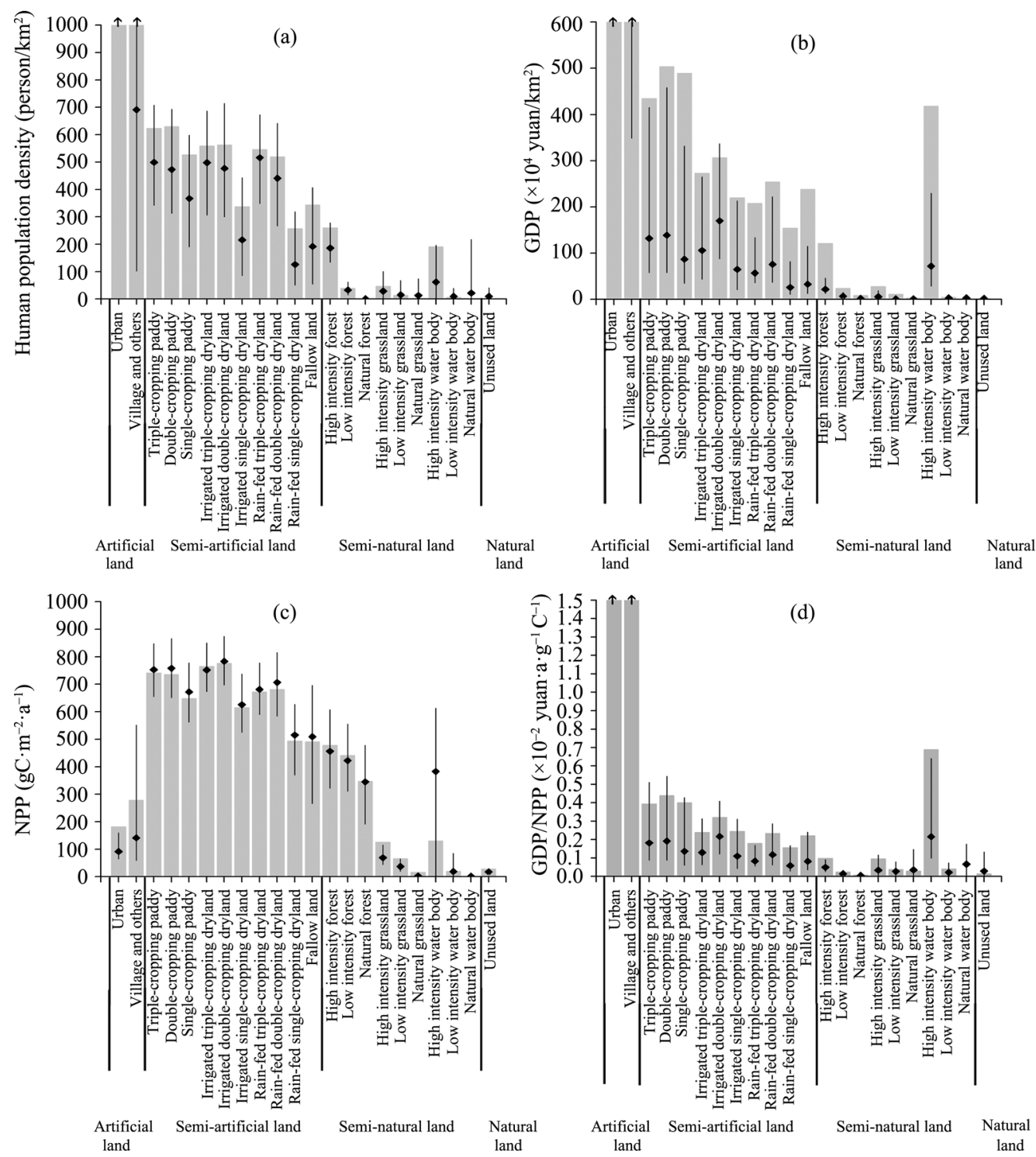

Figure 6 Statistics on population carrying capacity (a), economic carrying capacity (b), NPP (c), and land use efficiency (d) at the different levels of land use intensity. Bars represent the area-weighted means, diamonds are medians; error bars depict inter-quartile range. 
respectively. Artificial land supported $24.58 \%$ and $35.62 \%$ of the total population density and GDP, respectively, though it directly used only $0.71 \%$ of the total land area of China. The average population and economic carrying capacity of semi-artificial land was lower than that of artificial land. Although it accounted for just $19.36 \%$ of the total area in China, semi-artificial land supported $58.24 \%$ and $49.61 \%$ of the human population and GDP output, respectively. Population and economic carrying capacity of semi-natural land ranked third, with average values of 39.23 persons $/ \mathrm{km}^{2}$ and $26.25 \times 10^{4}$ yuan $/ \mathrm{km}^{2}$, supporting $16.89 \%$ and $14.36 \%$ of the human population and GDP, respectively. Natural land had the lowest carrying capacity for human population and economy. Furthermore, population and economic carrying capacity decreased across the subclasses of land use intensity. Specifically, the median value of human and economic carrying capacity decreased with a decline in the cropping intensity of cropland. Similar trends were also detected for forest, grassland, and water body.

Shown in Figure $6 \mathrm{c}$ is the significant variation of NPP among the different land use intensity classes. Semi-artificial land had the highest value of average NPP (235.14 $\left.\mathrm{g} \mathrm{Cm}^{-2} \mathrm{a}^{-1}\right)$, which accounted for $49.18 \%$ of the total NPP. This is undoubtedly because agricultural practices, such as multiple cropping, irrigation and fertilizer use, have greatly increased the NPP of semi-artificial land by increasing the latter's yields. In supporting $49.35 \%$ of the total NPP, semi-natural land had an average NPP of $201.53 \mathrm{~g} \mathrm{Cm}^{-2} \mathrm{a}^{-1}$, which was lower than that from semi-artificial land. Although semi-natural lands such as evergreen broadleaf forest and mixed broadleaf forests had higher NPPs than did semi-artificial land, the sparse forest, shrubs and grassland in semi-natural land typically had lower average NPPs because they experience smaller and fewer human disturbances coupled to their lower vegetation coverage. Natural land had the lowest average NPP, at $28.11 \mathrm{~g} \mathrm{Cm}^{-2} \mathrm{a}^{-1}$, largely because of its sparse vegetation coverage and vulnerable physical conditions with low precipitation regimes.

The land use efficiency of semi-artificial lands averaged $0.26 \times 10^{-2} \mathrm{yuan} \cdot \mathrm{a} \cdot \mathrm{g}^{-1} \mathrm{C}^{-1}$. This value was higher than that for semi-natural land. Specific to semi-artificial land, multiple cropped land had a higher land use efficiency than did single-cropped land. Water body had the highest land use efficiency among the semi-natural lands because of its mosaic water body and other productive areas. Natural land had the lowest use efficiency, at less than

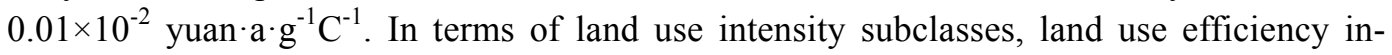
creased with land use intensity within semi-artificial, semi-natural, and natural lands (Figure $6 \mathrm{~d}$ ).

\section{Conclusions and discussion}

\subsection{Conclusions}

Status and changes in land use intensity, as well as their profound consequences on environmental land carrying capacity, have received increasing attention. By integrating remote sensing data with socio-economic data, a two-level hierarchical land use intensity classification system was constructed according to the intensity of human impacts in this study. Then, the land use intensity in China in 2000 at a $1-\mathrm{km}$ spatial resolution was obtained, and spatial patterns of land use intensity at national, regional, and provincial scales were also analyzed. Furthermore, the relationship between land use intensity and land carrying capacity was also explored. The main results from this study include: 
(1) Integrating information on land cover, human population distributions, and economic activities in agriculture, forestry, animal husbandry, and fishery, we constructed a two-level comprehensive land use intensity classification system. It could accurately represent the intensity of human modification on the Earth's land surface (in both space and time) according to the degree of surface disturbance by human activities and reversibility to natural land. The system included 4 classes and 22 nested subclasses. The main classes included artificial land, semi-artificial land, semi-natural land, and natural land. Artificial land was sub-classified based on the population distribution and degree of landscape fragmentation. Semi-artificial land was sub-classified based on information concerning the water conditions and cropping intensity. Semi-natural land was sub-classified considering the human population density and livestock population density. The cumulative area proportions of artificial land, semi-artificial land, semi-natural land and natural land were $0.71 \%, 19.36 \%, 58.93 \%$, and $21 \%$, respectively.

(2) Generally, land use in southeastern China, with its denser human population, was more intensive than that in the northwestern part with its sparse population. Huang-Huai-Hai Region had the largest area of artificial land but was inferior to Middle and Lower Reaches of the Yangtze River Region in its land use intensity. Semi-artificial land was widely distributed in Huang-Huai-Hai Region, Middle and Lower Reaches of the Yangtze River Region, and Northeast Region, but most intensively used in Middle and Lower Reaches of the Yangtze River Region, South China Region, and Sichuan Basin. Qinghai-Tibet Region had the largest area of semi-natural land. Natural land with the lowest intensity was concentrated in Gan-Xin Region and Qinghai-Tibet Region.

(3) Human and economic carrying capacity and land use efficiency increased with land use intensity. Artificial land had the highest human and economic carrying capacity and land use efficiency, supporting $24.58 \%$ and $35.62 \%$ of the total population density and GDP, respectively (using just $0.71 \%$ of the total land in China). Semi-artificial land supported $58.24 \%$ and $49.61 \%$ of human population and GDP using $19.36 \%$ of China's total land area. Semi-artificial land had the highest value of average NPP, accounting for $49.18 \%$ of the total NPP. Semi-natural land had lower land use efficiency, but it contributed more NPP supply than did semi-artificial land.

\subsection{Discussion}

There are several noteworthy differences between the present study and previous research on land use intensity classification systems and mapping. (1) We selected land use intensity metrics that were related to specific land cover types, e.g., grazing intensity of grassland was directly determined by livestock population density (Briske et al., 2015); felling intensity of forest was closely related to human population density (Pahari and Murai, 1999). (2) For cropland cover, we also investigated the cropping intensity, an important metric of cropping frequency (Erb et al., 2014), to better measure cropland use intensity. (3) We presented a high-resolution map quantifying the spatial distribution of land use intensity. Indicators used in measuring land use intensity were derived at a $1-\mathrm{km}$ spatial resolution, except cropping intensity (resampled from $500 \mathrm{~m}$ to $1 \mathrm{~km}$ to be consistent with other indicators). The $1-\mathrm{km}$ spatial resolution resultant map would effectively characterize the spatial heterogeneity of land use intensity and thus could help reduce uncertainty in earth system simulations. Unlike 
current domestic research focusing on cropland and urban areas, our study took all land use types into account - this provided systematic and objective information for the impact assessment of land use pattern and intensity on ecosystem resources and environmental carrying capacity. Compared with previous land-change studies, that examined changes in land cover, our research focused on land use intensity, by integrating natural and human drivers of land system change to provide robust and much-needed spatial datasets for a deeper understanding of the underlying drivers and causes of historical changes in land systems and the impact upon them from human activities. Land use intensity is a paramount factor affecting land use efficiency and land carrying capacity. Quantifying the relationship among them is of crucial and prime theoretical importance to better explore, understand, and discover land use change and sustainable land management options.

\section{References}

Allan E, Bossdorf O, Dormann C F et al., 2014. Interannual variation in land-use intensity enhances grassland multidiversity. Proceedings of the National Academy of Sciences of the United States of America, 111(1): 308-313.

Anderson J R, Hardy E E, Roach J T et al., 1976. A land use and land cover classification system for use with remote sensor data. US Geological Survey Professional Paper 964.

Blüthgen N, Dormann C F, Prati D et al., 2012. A quantitative index of land-use intensity in grasslands: Integrating mowing, grazing and fertilization. Basic and Applied Ecology, 13(3): 207-220.

Boserup E, 1965. The Conditions of Agricultural Growth: The Economics of Agrarian Change under Population Pressure. Chicago: Aldine Press.

Briske D D, Zhao M L, Han G D et al., 2015. Strategies to alleviate poverty and grassland degradation in Inner Mongolia: Intensification vs production efficiency of livestock systems. Journal of Environmental Management, 152: 177-182.

Burney J A, Davis S J, Lobell D B, 2010. Greenhouse gas mitigation by agricultural intensification. Proceedings of the National Academy of Sciences of the United States of America, 107(26): 12052-12057.

Chen Y Q, Li X B, 2009. Structural change of agricultural land use intensity and its regional disparity in China. Acta Geographica Sinica, 64(4): 469-478. (in Chinese)

Dai Y D, Zhu Y Z, 2013. Remodeling energy for sustainable development in China. Bulletin of Chinese Academy of Sciences, 2: 239-246. (in Chinese)

Ellis E C, Klein Goldewijk K, Siebert S et al., 2010. Anthropogenic transformation of the biomes, 1700 to 2000. Global Ecology and Biogeography, 19(5): 589-606.

Ellis E C, Ramankutty N, 2008. Putting people in the map: Anthropogenic biomes of the world. Frontiers in Ecology and the Environment, 6(8): 439-447.

Erb K H, Haberl H, Rudbeck M, 2013. A conceptual framework for analysing and measuring land-use intensity. Current Opinion in Environmental Sustainability, 5(5): 464-470.

Erb K, Niedertscheider M, Dietrich J P et al., 2014. Conceptual and empirical approaches to mapping and quantifying land-use intensity. In: Fischer-Kowalski M, Reenberg A, Schaffartzik A et al., eds. Ester Boserup's Legacy on Sustainability. New York: Springer, 61-86.

Fang C L, Wang Y, 2015. A comprehensive assessment of urban vulnerability and its spatial differentiation in China. Acta Geographica Sinica, 70(2): 234-247. (in Chinese)

FAOSTAT (Food and Agriculture Organization of the United Nations, Statistical Databases), 2011. FAOSTAT, FAO Statistical Databases: Agriculture, Fisheries, Forestry, Nutrition.

Foley J A, Ramankutty N, Brauman K A et al., 2011. Solutions for a cultivated planet. Nature, 478: 337-342.

Friedl M A, Sulla-Menashe D, Tan B et al., 2010. MODIS Collection 5 global land cover: Algorithm refinements 
and characterization of new datasets. Remote Sensing of Environment, 114(1): 168-182.

Green R E, Cornell S J, Scharlemann J P W et al., 2005. Farming and the fate of wild nature. Science, 307(5709): $550-555$.

Hao H G, Li X B, 2011. Agricultural land use intensity and its determinants in ecologically-vulnerable areas in North China: a case study of Taipusi County, Inner Mongolia Autonomous Region. Journal of Resource Ecology, 2(2): 117-125.

Hua X B, Yan J Z, Wang Q et al., 2013. Comparative analysis on influencing factors of cultivated land use intensity in valley and middle mountain area of upper Dadu River watershed. Transactions of the Chinese Society of Agricultural Engineering, 29(20): 234-244. (in Chinese)

Jiang L, Deng X Z, Seto K C, 2013. The impact of urban expansion on agricultural land use intensity in China. Land Use Policy, 35: 33-39.

Kuemmerle T, Erb K, Meyfroidt P et al., 2013. Challenges and opportunities in mapping land use intensity globally. Current Opinion in Environmental Sustainability, 5(5): 1-10.

Laliberté E, Wells J, DeClerck F et al., 2010. Land use intensification reduces functional redundancy and response diversity in plant communities. Ecology Letters, 13(1): 76-86.

Lambin E F, Rounsevell M D A, Geist H J, 2000. Are agricultural land-use models able to predict changes in land-use intensity? Agriculture, Ecosystems and Environment, 82(1-3): 321-331.

Lambin E F, Turner B L, Geist H J et al., 2001. The causes of land-use and land-cover change: Moving beyond the myths. Global Environmental Change, 11(4): 261-269.

Li G D, Fang C L, 2014. Quantitative measure and influencing mechanism of land intensive use in China at the county level. Acta Geographica Sinica, 69(12): 1739-1752. (in Chinese)

Li H M, Aide T M, Ma Y X et al., 2007. Demand for rubber is causing the loss of high diversity rain forest in SW China. Biodiversity and Conservation, 16(6): 1731-1745.

Liu C W, Li X B, 2006. The changing characteristics of the agricultural land use intensity in China based on the production cost. Journal of Natural Resources, 21(1): 9-15. (in Chinese)

Liu J Y, Kuang W H, Zhang Z X et al., 2014. Spatiotemporal characteristics, patterns, and causes of land-use changes in China since the late 1980s. Journal of Geographical Sciences, 24(2): 195-210.

Liu J Y, Zhang Z X, Xu X L et al., 2010. Spatial patterns and driving factors of land use change in China during the early 21 st century. Journal of Geographical Sciences, 20(4): 483-494.

Pahari K, Murai S, 1999. Modelling for prediction of global deforestation based on the growth of human population. The ISPRS Journal of Photogrammetry and Remote Sensing, 54(5/6): 317-324.

Petz K, Alkemade R, Bakkenes M et al., 2014. Mapping and modelling trade-offs and synergies between grazing intensity and ecosystem services in rangelands using global-scale datasets and models. Global Environmental Change, 29: 223-234.

Pittman K, Hansen M C, Becker-Reshef I et al., 2010. Estimating global cropland extent with multi-year MODIS data. Remote Sensing, 2(7): 1844-1863.

Robinson T P, Wint G R W, Conchedda G et al., 2014. Mapping the global distribution of livestock. PLoS One, 9(5): 1-3.

Sala O E, Chapin F S, Armesto J J et al., 2000. Global biodiversity scenarios for the year 2100. Science, 287(5459): 1770-1774.

Shriar A J, 2005. Determinants of agricultural intensity index "scores" in a frontier region: An analysis of data from northern Guatemala. Agriculture and Human Values, 22(4): 395-410.

Song X Q, Ouyang Z, 2012. Key influences factors of food security guarantee in China during 1999-2007. Acta Geographica Sinica, 67(6): 793-803. (in Chinese)

Stone G D, 2001. Theory of the square chicken: Advances in agricultural intensification theory. Asia Pacific Viewpoint, 2001, 42(2/3): 163-180.

Thenkabail P S, Biradar C M, Noojipady P et al., 2009. Global Irrigated Area Map (GIAM), derived from remote sensing, for the end of the last millennium. International Journal of Remote Sensing, 30(14): 3679-3733.

Thenkabail P S, Hanjra M A, Dheeravath V et al., 2011. Global croplands and their water use remote sensing and 
non-remote sensing perspectives. In: Weng Q H eds. Advances in Environmental Remote Sensing: Sensors, Algorithms, and Applications. Florida: CRC Press, Taylor and Francis Group, 383-419.

Václavík T, Lautenbach S, Kuemmerle T et al., 2013. Mapping global land system archetypes. Global Environmental Change, 23(6): 1637-1647.

van Asselen S, Verburg P H, 2012. A land system representation for global assessments and land-use modeling. Global Change Biology, 18(10): 3125-3148.

Verburg P H, Erb K H, Mertz O et al., 2013. Land system science: Between global challenges and local realities. Current Opinion in Environmental Sustainability, 5(5): 433-437.

Verburg P H, Mertz O, Erb K H et al., 2013. Land system change and food security: towards multi-scale land system solutions. Current Opinion in Environmental Sustainability, 5(5): 494-502.

Verburg P H, Van de Steeg J, Veldkamp A et al., 2009. From land cover change to land function dynamics: A major challenge to improve land characterization. Journal of Environmental Management, 90(3): 1327-1335.

Wu Y L, Qu F T, 2007. Mechanism of intensive urban land use in china: Theoretical and practical study. Resources Science, 29(6): 106-113. (in Chinese)

Xiao X M, Hollinger D, Aber J et al., 2004a. Satellite-based modeling of gross primary production in an evergreen needleleaf forest. Remote Sensing Environment, 89(4): 519-534.

Xiao X M, Zhang Q Y, Braswell B et al., 2004b. Modeling gross primary production of temperate deciduous broadleaf forest using satellite images and climate data. Remote Sensing of Environment, 91(2): 256-270.

Xie Y, Jiang Q B, 2016. Land arrangements for rural-urban migrant workers in China: Findings from Jiangsu Province. Land Use Policy, 50: 262-267.

Xu M Y, 2014. A review of grassland carrying capacity: Perspective and dilemma for research in China on forage-livestock balance. Acta Prataculturae Sinica, 23(5): 321-329. (in Chinese)

Xu X L, Shi P J, Yang M C, 2003. The impact of the national land policy on the sustainable arable land use in China since 1949. Journal of Beijing Normal University (Social Science Edition), 2: 115-123. (in Chinese)

Yan H M, Huang H Q, Xiao X M et al., 2008. Spatio-temporal distribution of multiple cropping system s in the Poyang Lake region. Acta Ecologica Sinica, 28(9): 4517-4523. (in Chinese)

Yan H M, Xiao X M, Huang H Q et al., 2014. Multiple cropping intensity in China derived from agro-meteorological observations and MODIS data. Chinese Geographical Science, 24(2): 205-219.

Yan H M, Xiao X M, Huang H Q, 2010. Satellite observed crop calendar and its spatio-temporal characteristics in multiple cropping area of Huang-Huai-Hai Plain. Acta Ecologica Sinica, 30(9): 2416-2423. (in Chinese)

Yao C S, Huang L, Lü X et al, 2014. Temporal and spatial change of cultivated land use intensity in China based on emergy theory. Transactions of the Chinese Society of Agricultural Engineering, 30(8): 1-12. (in Chinese)

Yu L, Wang J, Clinton N et al., 2013. FROM-GC: $30 \mathrm{~m}$ global cropland extent derived through multisource data integration. International Journal of Digital Earth, 6(6): 521-533.

Zhang F G, Hao J M, Jiang G H et al., 2005. Spatial-temporal variance of urban land use intensity. China Land Science, 19(1): 23-29. (in Chinese)

Zhang H Y, Fan J W, Shao Q Q, 2015. Land use/land cover change in the grassland restoration program areas in China, 2000-2010. Progress in Geography, 34(7): 840-853. (in Chinese)

Zhu H Y, Sun M H, 2014. Main progress in the research on land use intensification. Acta Geographica Sinica, 69(9): 1346-1357. (in Chinese) 